\title{
Continuity of Health, Citizen Empowerment as Key Driver
}

\author{
Jacob HOFDIJK ${ }^{\mathrm{a}, 1}$ and Felix CILLESSEN ${ }^{\mathrm{b}}$

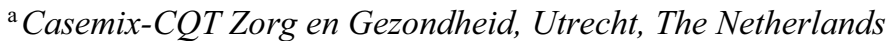 \\ ${ }^{b}$ Hospital Rivierenland Tiel, the Netherlands
}

\begin{abstract}
Self-management for prevention and care will play a significant role in the transition to apply person-centered care. Interoperability requirements, an overarching care plan, integration of social determinants, and the focus on prevention are important ingredients in the vision on its implementation.
\end{abstract}

Keywords. Care continuity, integrated health care systems, health maintenance

\section{Introduction}

The global strategy on people-centered care (PCC) and integrated health services from the World Health Organization is challenging [1]. Citizens have to play a major role in the fundamental paradigm shift it requires. The Covid-19 pandemic stimulates citizens as co-creator of the overarching objectives of their health and wellness. An interoperable holistic problem list (HPL) with interoperable subjective and objective data is vital for patients and providers in our vision to properly manage all health and social issues [2]. The most important value of any health care system should be the maintenance of health [3]. What next step is needed to intensify the PCC implementation?

\section{Methods}

Since the European Medical Informatics Conference 2012 in Pisa, various international workshops have been held in which the requirements for integrated care and the shift towards PCC were discussed. At the 2020 ICIMTH conference in Athens, the scope was broadened to prevention. To guarantee the continuity of care in combination with social distancing, health organizations are ramping up their telehealth. As the determinants of health are not only dependent on medical factors, but much more on factors like genetics, biology, life style, and social characteristics, a multifaceted less medical approach of prevention is required. From the concept of a HPL, the patient's story plays a key role to PCC.

\footnotetext{
${ }^{1}$ Corresponding Author, Jacob Hofdijk, Casemix-CQT Zorg en Gezondheid, Utrecht, The Netherlands; Email: jacob.hofdijk@casemix.nl
} 


\section{Results}

It takes technical and semantical interoperability of data and empathic design of systems, to shift to a technology enabled continuity of care concept. To combine them with the overarching care plan and the societal incentive program does form a solid foundation. The available subjective and objective data can be linked to an active PCC plan to reach and document common agreed health and/or social objectives. This approach helps the patient safeguard their health and with its providers better manage their active problems. The Blue Line Statement of the 2015 The Hague PCSI Conference recommends to continuously develop and formalize these principles as requirements for holistic, person-centered, integrated care systems.

\section{Discussion}

To manage the social determinants of health, sensitive personal data on social, lifestyle, and genetics issues have to be collected by citizens. The patient's story contributes to the continuity and transparency of the provider-patient partnership [4]. Full participation of the citizen will be dependent on the added value it brings to their health and care [5]. Policymakers and health system leaders need to adopt the necessary requirements by creating a societal incentive framework, like innovative funding to enable this vision. It will provide a base for regionally arranging the integrated service delivery as proposed by the WHO strategy for the benefit of both health maintenance and health and social care.

\section{Conclusion}

Applying the transition to PCC we promote the concept of continuity of health, which could start at birth and should be maintained all along the life path of the person. For each phase of life, the primary focus of the overarching holistic health and care plan should be on managing health and wellbeing, taking into account the actual risk factors. Continuity of health should thus be the driver to motivate citizens as data producers and service co-creators actively managing their health. Trust, participation, engagement, education, demonstrated benefits, and other sorts of incentives, associated with healthy life, will support this vision and stimulate the transition to its implementation.

\section{References}

1. WHO global strategy on people-centred and integrated health services 2015 [Available from: http://apps.who.int/iris/bitstream/10665/155002/1/WHO_HIS_SDS_2015.6_eng.pdf?ua=1\&ua=1, Accessed July 9, 2020.

2. Cillessen FH, Hofdijk J. Transition Requirements from Problem List to an Overarching Care Plan for the Support of Person-Centered Care. Stud Health Technol Inform. 2020;272:292-5.

3. Porter ME. What is value in health care? N Engl J Med. 2010;363(26):2477-81.

4. Ekman I, Swedberg K, Taft C, Lindseth A, Norberg A, Brink E, et al. Person-centered care--ready for prime time. Eur J Cardiovasc Nurs. 2011;10(4):248-51.

5. Cantor MN, Thorpe L. Integrating Data On Social Determinants Of Health Into Electronic Health Records. Health Aff (Millwood). 2018;37(4):585-90. 